\section{Attractiveness of Parboiled Rice Hulls to the Fungus Gnat, Bradysia sp. nr coprophila (Diptera: Sciaridae), Adult Relative to Standard Growing Medium}

\section{Components}

\author{
Raymond A. Cloyd ${ }^{1}$ \\ Kansas State University, Department of Entomology, 123 Waters Hall, \\ Manhattan, KS 66506-4004
}

Karen A. Marley and Richard A. Larson

University of Illinois, Department of Natural Resources and Environmental Sciences, Urbana, IL 61801

\section{Bari Arieli \\ Kansas State University, Department of Entomology, Manhattan, KS}

Additional index words. growing media, attraction, experimental arena, floriculture, steam distillation

\begin{abstract}
This study was conducted to assess the attractiveness of growing media containing parboiled rice hulls (PBH) to fungus gnat, Bradysia sp. nr. coprophila (Diptera: Sciaridae), adults. In comparing commercially prepared $\mathrm{PBH}$ with peatmoss (LC1) and pine bark (SB200)-based growing media, it was established that the fungus gnat adults were not specifically attracted to any of the growing media, even those containing $\mathrm{PBH}$, with the mean proportion of fungus gnat adults recovered in the sample compartments ranging from 0.16 to 0.23 . Moisture content was more important in terms of fungus gnat adult attractiveness to the growing media. In addition, the volatile constituents of the various growing media were determined using a steam distillation procedure. The component that was present in the highest concentration $(39.2 \%)$ in the dried PBH as determined by gas chromatography analysis was palmitic acid, a straightchain C16 fatty acid. S8 (cyclo-octasulfur), a well-known odoriferous component of degraded waste materials, was present at a higher concentration $(6.2 \%)$ in the RH1 growing medium (80\% peatmoss) compared with the other growing media evaluated. The data indicate that $\mathrm{PBH}$, when incorporated in certain growing media, do not attract fungus gnat adults, and as such, greenhouse producers can use $\mathrm{PBH}$ as an amendment to growing medium without having to be concerned with the prospect of luring fungus gnat adults and sustaining plant damage.
\end{abstract}

Fungus gnats (Bradysia spp.) are common insect pests of greenhouse-grown crops (Dennis, 1978; Hamlen and Mead, 1979). The adults are primarily considered a nuisance causing minimal actual plant damage (Cloyd, 2000), although the eggs laid by adult females hatch into larvae that are directly responsible for causing injury to plants by feeding on the roots (Fawzi and Kelly, 1982; Hungerford, 1916; Jarvis et al., 1993; Kennedy, 1971; Wilkinson and Daugherty, 1970). Growing media may vary in attracting

Received for publication 11 Mar. 2009. Accepted for publication 21 Apr. 2009.

We are grateful to SunGro Horticulture, Inc. (Bellevue, WA), in particular, Todd J. Cavins and Richard P. Vetanovetz, for providing financial support for this study. We also thank Dr. Kun Yan Zhu (Kansas State University, Manhattan, KS) for his initial review of the manuscript.

${ }^{1}$ To whom reprint requests should be addressed; e-mail rcloyd@ksu.edu. appear to be attracted to or prefer moist growing media containing peatmoss (Baker, 1994). This may provide an abundant level of fungal activity (Freeman, 1983; Olson et al., 2002), which is attractive to and serves as a food source for adult fungus gnats (Anas and Reeleder, 1988; Gardiner et al., 1990; Kennedy, 1974).

Parboiled rice hulls $(\mathrm{PBH})$ are a type of fresh rice hull derived specifically from parboiled rice that are obtained during a steaming process (Evans and Gachukia, 2008). It has been demonstrated that PBH may be an alternative to using perlite, which is an inorganic expanded aluminosilicate byproduct of volcanic origin (Nelson, 2003) incorporated into growing media to improve drainage and air-filled pore space. However, perlite is expensive to mine, transport, and heat. Furthermore, the dust emitted may irritate eyes and lungs (Gachukia and Evans, 2008). Parboiled rice hulls may be included in growing media used for the production of ornamental plants (Evans and Gachukia, 2004). Nonetheless, the potential attractiveness of $\mathrm{PBH}$ to fungus gnats is not known. This is important because any growing medium component that attracts fungus gnat adults may lead to significant crop damage as a result of feeding by the larvae. As such, the objective of this study was to determine the attractiveness of $\mathrm{PBH}$ to the fungus gnat, Bradysia sp. nr coprophila, adults compared with standard growing medium components under laboratory conditions.

\section{Materials and Methods}

A series of seven replicated experiments were conducted to ascertain whether $\mathrm{PBH}$ or growing media containing $\mathrm{PBH}$ are attractive to fungus gnat adults. Four different growing media were evaluated: Sunshine LC1 Mix ( $75 \%$ sphagnum peatmoss and $25 \%$ perlite), RH1 (80\% peatmoss and $20 \%$ rice hulls), SB200 (60\% peatmoss, $20 \%$ bark, and $20 \%$ perlite), and RH20 (100\% rice hulls). The growing media were supplied by SunGro Horticulture, Inc. All experiments were conducted in the absence of a light source because fungus gnat adults are attracted to light (Cloyd et al., 2007a). The equipment and methodology used in the experiments were similar to those described in Cloyd et al. (2007b), which involved the use of a set of five six-armed experimental arenas consisting of a central compartment made from a clear, round 5.3-L polypropylene microwavable container (Flex \& Seal ${ }^{\circledR}$; Rubbermaid, Inc., Fairlawn, $\mathrm{OH}$ ) accompanied by snap-on lids (Fig. 1).

Experimental procedures. Fungus gnat adults used in the study were obtained from laboratory colonies reared on SB300 Universal Professional Growing Mix (Cabrera et al., 2005). Fungus gnat adults used in all the experiments were 6 to $9 \mathrm{~d}$ old. Approximately 100 fungus gnat adults (mixture of females and males) were released into the central compartment of each experimental arena. Adults were aspirated into a 9-dram plastic 


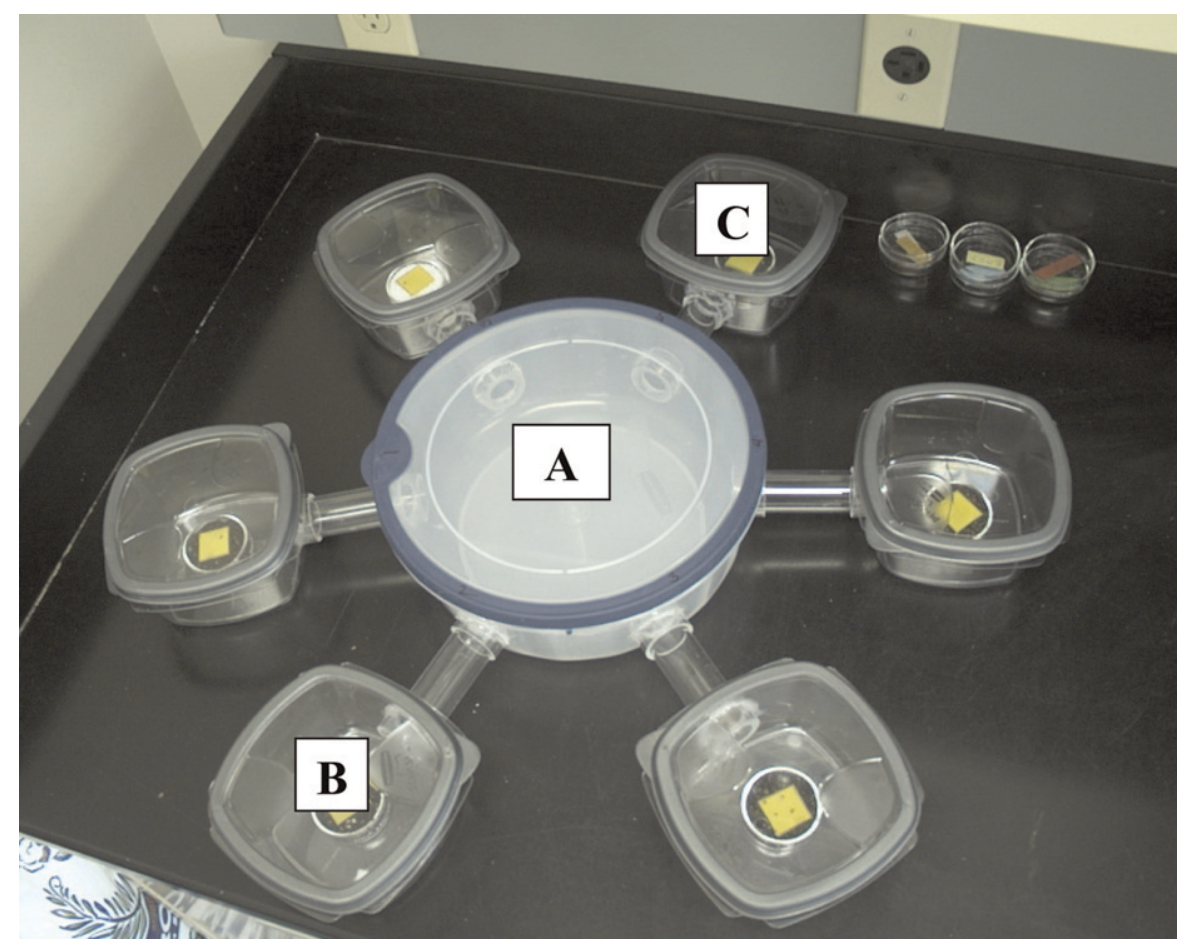

Fig. 1. Six-armed experimental arena used for all experiments in the study. A $60 \times 15-\mathrm{mm}$ glass petri dish containing the treatments (growing medium) was placed into the designated sample compartments (B or C). A $2.5 \times 2.5-\mathrm{cm}$ yellow sticky card was placed onto the surface of each treatment. Adult fungus gnats, Bradysia sp. nr. coprophila, obtained from a laboratory colony were collected in a 9-dram plastic vial and then placed into the central compartment (A). The number of adult fungus gnats captured on the yellow sticky cards and on the floor in the sample compartments ( $\mathbf{B}$ or $\mathbf{C}$ ) was used to measure the attractiveness of each treatment. In the multiple-choice experiment, we used four arms of the experimental arena, whereas in the two-choice experiments, two arms of the experimental arena (B and $\mathbf{C})$ were used.

vial (BioQuip Products, Rancho Dominguez, CA). The vial was placed in the middle of the central compartment, the vial lid was removed, and then the central compartment lid was quickly sealed.

All experiments were conducted in a laboratory room located in Waters Hall (Kansas State University), Manhattan, KS. The room temperature was $24 \pm 3{ }^{\circ} \mathrm{C}$. For the multiple-choice experiments, the experimental arenas were positioned on the floor of the laboratory with the treatments arranged randomly within each experimental arena. For the two-choice experiments, the experimental arenas were placed on a table $(1.8 \times 0.6 \mathrm{~m})$. Previous research has demonstrated that fungus gnat adults are attracted to light (Cloyd et al., 2007a) so the vials containing adult fungus gnats were placed into the central compartments with the room door slightly ajar (so it was possible to implement the procedure of releasing the fungus gnat adults into the central compartment); after all the vials had been placed into the central compartments, the door was closed. Yellow sticky cards $(2.5 \times$ $2.5 \mathrm{~cm}$ ) were positioned on the surface of each growing medium. The following experiments were performed in the study: Expt. 1 (rice hull growing medium versus perlite growing medium); Expt. 2 (moist versus moist growing medium - different growing media); Expt. 3 (moist versus moist growing mediumdifferent growing media); Expt. 4 (moist versus detector and confirmed by authentic standards (Sigma). Quantitative analysis was assessed by gas chromatography with a flame ionization detector.

Data analysis. Data were calculated per replicate as a proportion of the number of fungus gnat adults captured on the yellow sticky cards as well as those on the floor and flying around in each sample compartment out of the total number collected using a Statistical Software Program (SAS Systems for Windows, Version 8.2). For Expt. 1, data were normalized by arcsine square root transformation and subject to a one-way analysis of variance with sample compartment as the main effect (SAS Institute, 2002). Significant sample compartment means were separated using a Fisher's protected least significant difference test at $P=0.05$. For Expts. 2 through 7 , data were normalized by arcsine square root transformation and a $t$ test procedure (SAS Institute, 2002) was conducted to determine significant differences between the two treatments. All data presented are nontransformed.

\section{Results}

Expt. 1: Rice hull growing medium versus perlite growing medium. Treatment was not significant $(F=0.89 ; \mathrm{df}=3,39 ; P=0.454)$ as all the treatments (RH20, LC1, RH1, and SB200) had similar proportions of fungus gnat adults present in the sample compartments (Table 1). The range of fungus gnat adults collected from the colonies and used in the experiment was between 90 and 120 .

Expt. 2: Moist versus moist growing medium-different growing media. Treatment was significant $(t$ value $=2.61 ; \mathrm{df}=9$, $16 ; P=0.019$ ) with a higher proportion of fungus gnat adults present in the sample compartments containing moistened RH20 (41\%) compared with moistened SB200 $(31 \%)$. The range of fungus gnat adults collected from the colonies and used in the experiment was between 75 and 170 .

Expt. 3: Moist versus moist growing medium-different growing media. Treatment was not significant $(t$ value $=1.46$; df $=9,13.1 ; P=0.168$ ) with a similar proportion of fungus gnat adults present in the sample compartments containing either moistened LC1 $(39 \%)$ or moistened SB200 $(43 \%)$. The range of fungus gnat adults collected from the colonies and used in the experiment was between 75 and 130 .

Expt. 4: Moist versus moist growing medium-different growing media. Treatment was not significant $(t$ value $=0.75$; $\mathrm{df}=9,17.7 ; P=0.462$ ) with a similar proportion of fungus gnat adults present in the sample compartments containing either moistened RH1 (36\%) or moistened SB200 $(41 \%)$. The range of fungus gnat adults collected from the colonies and used in the experiment was between 95 and 160 .

Expt. 5: Moistened versus dry growing medium. Treatment was significant $(t$ value $=$ 6.76; df $=9,16 ; P<0.0001)$ with a higher proportion of fungus gnat adults present in 
Table 1. Mean ( \pm SEM) proportion of fungus gnat, Bradysia sp. nr. coprophila, adults recovered in the sample compartments associated with each experimental arena for each growing medium treatment in Expt. 1 ( $\mathrm{n}=$ number of replications per treatment).

\begin{tabular}{lcc}
\hline Treatment (growing medium) & $\mathrm{n}$ & $\begin{array}{c}\text { Mean }( \pm \text { sEM) proportion fungus } \\
\text { gnat adults recovered }\end{array}$ \\
\hline RH20 & 10 & $0.21 \pm 0.03 \mathrm{a}^{\mathrm{z}}$ \\
LC1 & 10 & $0.22 \pm 0.03 \mathrm{a}$ \\
RH1 & 10 & $0.23 \pm 0.03 \mathrm{a}$ \\
SB200 & 10 & $0.16 \pm 0.02 \mathrm{a}$ \\
\hline
\end{tabular}

${ }^{\mathrm{z}}$ Means followed by common letter are not significantly different based on a Fisher's protected least significant difference test with $P \leq 0.05$.

the sample compartments containing moistened SB200 (52\%) than sample compartments containing dry RH20 (17\%). The range of fungus gnat adults collected from the colonies and used in the experiment was between 80 and 140 .

Expt. 6: Moist versus moist growing medium-different growing media. Treatment was not significant $(t$ value $=0.32$; $\mathrm{df}=9,17.9 ; P=0.750)$ with a similar proportion of fungus gnat adults present in the sample compartments containing either moistened RH1 (34\%) or moistened LC1 $(32 \%)$. The range of fungus gnat adults collected from the colonies and used in the experiment was between 100 and 170 .

Expt. 7: Moist versus moist growing medium-same growing medium. Treatment was significant $(t$ value $=4.57, \mathrm{df}=9,17 ; P=$ 0.003 ) with a higher proportion of fungus gnat adults present in the sample compartments containing moistened RH20 (53\%) than sample compartments containing dry RH20 (17\%). The range of fungus gnat adults collected from the colonies and used in the experiment was between 110 and 180 .

Steam distillation procedure. The rice hull material had very little, if any, discern- ible odor. RH1 had an odor similar to ordinary peatmoss. LC1, which contains $\approx 75 \%$ sphagnum peatmoss, had more of a "mushroom"-like odor and the growing medium SB200 had an "earthy" odor. In general, the aqueous steam distillate of each of these materials had an odor quite similar to "peatmoss."

Results of the gas chromatography-flame ionization detector analysis are presented in Table 2. The major components identified were very similar to the types of compounds previously identified from a commercial peatmoss material (Cloyd et al., 2007b). Those components that were present included the fatty acids, C6-C18, and the dicarboxylic acids, C4-C5 as well as furfural and 5-methylfurfural. Cyclosulfur (S8) was present in each of the commercially mixed growing media, but not in the rice hull material. The rice hull material contained nearly 10 times as much $\mathrm{C} 16(39.2 \%)$ as the other growing media tested (Table 2).

\section{Discussion}

This study demonstrated that PBH are not attractive to fungus gnat adults. What appears

Table 2. Percent composition of volatiles detected in rice hulls and growing media using steam distillation procedure as determined by gas chromatography (GC) analysis.

\begin{tabular}{|c|c|c|c|c|c|}
\hline Compound & $\begin{array}{l}\text { Rice hulls } \\
\text { (dry) }\end{array}$ & RH1 (dry) & RH20 (dry) & LC1 (dry) & $\begin{array}{l}\text { SB200 universal mix } \\
\text { (dry) }\end{array}$ \\
\hline \multicolumn{6}{|l|}{ Dicarboxylic acids $^{z}$} \\
\hline $\mathrm{C} 4$ & 0.2 & 0.3 & 1.5 & 0.3 & 0.2 \\
\hline $\mathrm{C} 5$ & 0.1 & 0.4 & 1.4 & 0.9 & 1.3 \\
\hline C6 & NP & NP & NP & NP & NP \\
\hline $\mathrm{C} 7$ & NP & NP & 0.1 & NP & NP \\
\hline $\mathrm{C} 8$ & NP & 0.1 & 0.6 & NP & NP \\
\hline \multicolumn{6}{|l|}{ Alkanoic fatty acids ${ }^{z}$} \\
\hline C6 & 1.9 & 0.6 & 0.3 & NP & 0.8 \\
\hline $\mathrm{C} 7$ & 0.4 & 0.6 & 0.1 & 0.8 & 0.5 \\
\hline $\mathrm{C} 8$ & 2.5 & 0.6 & 1.2 & 5.3 & 3.8 \\
\hline $\mathrm{C} 9$ & 1.8 & 0.6 & 0.1 & 0.8 & 0.7 \\
\hline $\mathrm{C} 10$ & 0.4 & 0.3 & 0.2 & 0.4 & 0.4 \\
\hline $\mathrm{C} 11$ & 0.1 & 0.2 & 0.1 & 0.2 & NP \\
\hline $\mathrm{C} 12$ & 1.7 & 1.5 & 0.7 & 1.1 & NP \\
\hline $\mathrm{C} 14$ & 3.1 & 0.3 & 1.7 & 0.7 & 0.6 \\
\hline $\mathrm{C} 16$ & 39.2 & 2.0 & 7.8 & 1.0 & 2.9 \\
\hline C18 & 1.3 & 0.8 & 0.7 & 0.5 & 0.4 \\
\hline Furfural & 0.2 & 2.8 & NP & 10.1 & 3.9 \\
\hline Methyl furfural & 0.2 & 1.5 & NP & 2.1 & 1.8 \\
\hline Camphor & NP & 0.1 & NP & NP & NP \\
\hline Verbenone & NP & 0.5 & NP & NP & 0.4 \\
\hline 1,3-dimethoxybenzene & NP & 0.1 & NP & NP & 0.4 \\
\hline Dodecanol & 0.2 & 2.3 & 0.9 & 1.4 & 0.9 \\
\hline Cyclosulfur (S8) & NP & 6.2 & 0.1 & 0.1 & 0.6 \\
\hline
\end{tabular}

${ }^{\mathrm{z}}$ Determined as methyl ester.

$\mathrm{NP}=$ not present based on gas chromatography-flame ionization detector or gas chromatography-mass selective detector. to be most important in terms of fungus gnat adult attractiveness is the growing medium moisture content. In our study, fungus gnat adults were attracted to moist growing media and were less attracted to growing media with low moisture contents (less than 10\%), which may be associated with survival of fungus gnat eggs and larvae (Cloyd and Dickinson, 2008; Ellisor, 1934). Furthermore, Olson et al. (2002) determined that fungus gnat larval survival was higher in a peat-based growing medium (35\% to $45 \%$ sphagnum peatmoss) with a moisture content between $52 \%$ and $71 \%$ compared with growing media with a moisture content less than $34 \%$ and maintained at $90 \%$.

The growing media RH1 and RH20 are blends from a commercial vendor (SunGro Horticulture, Inc.) with $20 \%$ and $100 \% \mathrm{PBH}$, respectively. Although the $\mathrm{RH} 20$ growing medium is supposed to contain $100 \% \mathrm{PBH}$, there were trace amounts of peatmoss present, enough so that a "characteristic" peatmoss-like odor was detectable before analysis. Consequently, a purer sample of $\mathrm{PBH}$, with no peatmoss present, was obtained from the vendor. There was no discernible odor from this new material. The most abundant constituent that was present in the highest concentration in the dried $\mathrm{PBH}$ as determined by gas chromatography analysis was n-C16 (palmitic acid). Palmitic acid, a saturated straight-chain acid, is commonly present in plant material. The higher concentrations obtained in the rice hulls most likely indicate that this material has not undergone sufficient physical decay with the hulls still intact. In materials such as peatmoss or composted bark that are exposed to a specific degradation treatment, the long chain fatty acids are fragmented into shorter chains or more oxidized components.

Previous studies have demonstrated that crop residues from rice fields or composted rice hulls contain numerous secondary metabolites (see review by Rimando and Duke, 2003). The PBH used in this study and subsequent experiments were cleaned and subjected to heat by the manufacturer, which is similar to treatments that produce composted bark, thus providing a material that may be incorporated into growing medium. To assess the odoriferous components of growing media, which may act as lures for fungus gnat colonization, this study focused on the volatile constituents. Aqueous or organic solvent extracts of rice residue (or any plant residue) should yield the very complex phenolics, triterpenes, and steroidal constituents, which have been identified in rice (Oryza sativa L.). However, none of these compounds were detected in the collected steam distillate. Instead, fatty acids, primarily palmitic (C16) and stearic (C18) acid, were the main constituents with small amounts of shorter-chain fatty acids and diacids (Table 2). Minimal quantities of furfural and methylfurfural as well as dodecanol were also detected. Both the RH1 and RH20 material had similar profiles; however, additional volatiles were also present, which 
were detected in the LC1 and SB200 material. Furthermore, cyclosulfur (S8) was detected in each of the commercially available growing media with the highest amount in the RH1 growing medium ( $80 \%$ peatmoss).

A number of analytical techniques are available to characterize odor profiles. Steam distillation has proven to be sufficient in obtaining samples from various soilless growing media that contain a range of plant-based constituents such as terpenes and phenolics as well as the volatile cellular breakdown products such as diacids and fatty acids. Previous research with peatmoss and composted pine bark has demonstrated that the C6-C18 fatty acids are more prevalent in peatmoss material (Cloyd et al., 2007b). In the previous research as well as our current study, the more pungent acids such as propionic or butyric acid were not present.

Evidence of microbial transformation in the composted materials can also be revealed in these volatile analyses. Composted pine bark would be expected to contain pinene and camphene, but instead borneol and alphaterpineol, which are both microbial metabolites of the two terpenes (Braddock and Cadwallader, 1995), were present. Cyclosulfur (S8) was detected in each of the materials that contained peatmoss: RH1, RH20, LC1, and SB200. This pungent off-odor compound may be formed by bacterial oxidation of hydrogen sulfide (Steudel, 1996).

Experimental arenas such as the one used in our study are a common method to quantify the attraction of compounds to insects under laboratory conditions (Gothilf and Galun, 1982; Martin et al., 1990). Moreover, it was essential to conduct all the experiments in the laboratory so as to determine insect responses and eliminate any unknown variables or confounding factors that could have occurred under field conditions. We also used types of plastic (polypropylene and acrylic) that do not emit detectable volatiles, which could have influenced our results.

This study was designed to assess the attractiveness of PBH when incorporated in growing media to fungus gnat adults. As such, we have demonstrated that Bradysia sp. nr. coprophila adults do not appear to prefer PBH when compared with other growing medium components. This indicates that greenhouse producers may use $\mathrm{PBH}$ as an amendment to growing medium without having to be concerned with the prospect of luring fungus gnat adults and sustaining plant damage.

\section{Literature Cited}

Anas, O. and R.D. Reeleder. 1988. Feeding habits of Bradysia coprophila on fungi and plant tissue. Phytoprotection 69:73-78.
Baker, J.R. 1994. Insects and related pests of flowers and foliage plants, AG-136. North Carolina Cooperative Extension Service, North Carolina State University, Raleigh, NC.

Braddock, R.J. and K.R. Cadwallader. 1995. Bioconversion of citrus d-limonene, p. 142-147. In: Rouseff, R.C., and M.M. Leahy (eds.) Fruit flavors: Biogenesis, characterization and athentication. ACS Symposium Series 596. American Chemical Society, Washington, DC.

Cabrera, A.R., R.A. Cloyd, and E.R. Zaborski. 2005. Development and reproduction of Stratiolaelaps scimitus (Acari: Laelapidae) with fungus gnat larvae (Diptera: Sciaridae), potworms (Oligochaeta: Enchytraeidae) or Sancassania aff. sphaerogaster (Acari: Acaridae) as the sole food source. Exp. Appl. Acarol. 36:71-81.

Cloyd, R.A. 2000. Fungus gnat and shorefly management strategies: Panel discussion, p. 57-59. In: King, A.I., and I.D. Greene (eds.). Proc. of 16th Conference on Insect and Disease Management on Ornamentals. Society of American Florists, Alexandria, VA.

Cloyd, R.A. and A. Dickinson. 2008. Procedure to enhance the recovery rate of fungus gnat, Bradysia sp. nr. coprophila Lintner (Diptera: Sciaridae) adults from growing medium. HortScience 43:1528-1530.

Cloyd, R.A., A. Dickinson, R.A. Larson, and K.A. Marley. 2007a. Phototaxis of fungus gnat, Bradysia sp. nr coprophila (Lintner) (Diptera: Sciaridae), adults to different light intensities. HortScience 42:1217-1220.

Cloyd, R.A., A. Dickinson, R.A. Larson, and K.A. Marley. 2007b. Effect of growing media and their constituents on fungus gnat, Bradysia sp. nr. coprophila (Lintner) adults. Insect Sci. 14:467-475.

Dennis, D.J. 1978. Observations of fungus gnat damage to glasshouse cucurbits. N. Z. J. Exper. Agr. 6:83-84.

Ellisor, L.O. 1934. Notes on the biology and control of Neosciara ocellaris (Comstock) (Diptera: Sciaridae). Iowa State J. Sci. 9:2536.

Evans, M.R. and M.M. Gachukia. 2004. Fresh parboiled rice hulls serve as an alternative to perlite in greenhouse crop substrates. HortScience 39:232-235.

Evans, M.R. and M.M. Gachukia. 2008. Secondary macro- and microelements in Sphagnum peatbased substrates amended with parboiled fresh rice hulls or perlite. HortTechnology 18:650 655.

Fawzi, T.H. and W.C. Kelly. 1982. Cavity spot of carrots caused by feeding of fungus gnat larvae. J. Amer. Soc. Hort. Sci. 107:11771181.

Freeman, P. 1983. Sciarid flies, 68 pp. In: Fitton, M.G. (ed.). Handbook for the identification of British insects. Vol. 9, Part 6. Royal Entomological Society of London, London, UK.

Hamlen, R.A. and F.W. Mead. 1979. Fungus gnat larval control in greenhouse plant production. J. Econ. Entomol. 72:269-271.

Hungerford, H.B. 1916. Sciari maggots injurious to potted plants. J. Econ. Entomol. 9:538549 .
Gachukia, M.M. and M.R. Evans. 2008. Root substrate $\mathrm{pH}$, electrical conductivity, and macroelement concentration of sphagnum peatbased substrates amended with parboiled fresh rice hulls or perlite. HortTechnology 18:644 649.

Gardiner, R.B., W.R. Jarvis, and J.L. Shipp. 1990. Ingestion of Pythium spp. by larvae of fungus gnat Bradysia impatiens (Diptera: Sciaridae). Ann. Appl. Biol. 116:205-212.

Gothilf, S. and R. Galun. 1982. Olfactometer and trap for evaluating attractants for the Mediterranean fruit fly, Ceratitis capitata. Phytoparasitica 10:79-84.

Jagdale, G.B., M.L. Casey, P.S. Grewal, and R.K. Lindquist. 2004. Application rate and timing, potting medium, and host plant effects on the efficacy of Steinernema feltiae against the fungus gnat, Bradysia coprophila, in floriculture. Biol. Control 29:296-305.

Jarvis, W.R., J.L. Shipp, and R.B. Gardiner. 1993. Transmission of Pythium aphanidermatum to greenhouse cucumber by the fungus gnat $\mathrm{Bra}$ dysia impatiens (Diptera: Sciaridae). Ann. Appl. Biol. 122:23-239.

Kennedy, M.K. 1971. The significance of fungi in the ecology of Bradysia impatiens. Cornell University, Ithaca, NY. MS Thesis.

Kennedy, M.K. 1974. Survival and development of Bradysia impatiens (Diptera: Sciaridae) on fungal and non-fungal food sources. Ann. Entomol. Soc. Amer. 67:745-749.

Lindquist, R.K. 1994. Integrated management of fungus gnats and shore flies, p. 19-21. In: Robb, K. (ed.). Proc. of 10th conference on insect and disease management on ornamentals. Society of American Florists, Alexandria, VA.

Martin, W.R., Jr., D.A. Nordlund, and W.C. Nettles, Jr. 1990. Response of parasitoid Eucelatoria bryani to selected plant material in an olfactometer. J. Chem. Ecol. 16:499-508.

Meers, T.L. and R.A. Cloyd. 2005. Egg-laying preference of female fungus gnat Bradysia sp. nr. coprophila (Diptera: Sciaridae) on three different soilless substrates. J. Econ. Entomol. 98:1937-1942.

Nelson, P.V. 2003. Greenhouse operation and management. 5th Ed. Prentice Hall, Upper Saddle River, NJ.

Olson, D.L., R.D. Oetting, and M.W. van Iersel. 2002. Effect of soilless potting media and water management on the development of fungus gnats (Diptera: Sciaridae) and plant growth HortScience 37:919-923.

Rimando, A.M. and S.O. Duke. 2003. Rice: Origin, history, technology, and production, 221-244. In: Smith, C.W., and R.H. Dilday (eds.). Wiley series in crop science. John Wiley \& Sons, Inc., Hoboken, NJ

SAS Institute. 2002. SAS/STAT users guide, Version 8.2. SAS Institute, Inc., Cary, NC.

Steudel, R. 1996. Mechanism for the formation of elemental sulfur from aqueous sulfide in chemical and microbiological desulfurization processes. Ind. Eng. Chem. Res. 35:14171423 .

Wilkinson, J.D. and D.M. Daugherty. 1970. The biology and immature stages of Bradysia impatiens (Diptera: Sciaridae). Ann. Entomol. Soc. Amer. 63:656-660. 